\title{
Key factors in tissue engineering
}

\author{
YOSHITO IKADA \\ Institute for Frontier Medical Sciences, Kyoto University, 53, Kawara-cho Shogoin, Sakyo-ku, Kyoto 606-8507, \\ Japan
}

\begin{abstract}
Tissue engineering is an emerging biomedical form of engineering aiming at regeneration of natural tissues or creation of biological substitutes for defective or lost tissues and organs using cells of different species. It is essential for the tissue self-regeneration, for instance, to provide a space necessary for regeneration with certain materials and technologies. This article overviews such key factors required for tissue engineering.
\end{abstract}

Keywords. Tissue regeneration; tissue substitution; scaffold; release carrier of growth factor; barrier; blast cells.

\section{What is tissue engineering?}

Because of a short history of tissue engineering, this field is not yet clearly defined. It would be, therefore, helpful to give a brief explanation on tissue engineering. The objective of tissue engineering is to regenerate natural tissues or construct biological substitutes for defective tissues and organs using homo- or heterogeneous cells. As is shown in figure 1 , the activity of tissue engineering includes two categories: self-regeneration of tissues with autogeneic cells and organ substitution with foreign cells. The latter is called bioartificial organ. Thus, tissue engineering research requires combination of a variety of sciences and technologies including clinical medicine, cell biology, biomaterials, and biotechnology. This is in marked contrast with the research on conventional artificial tissues and organs. This reconstructive medicine entirely depends on man-made materials. Further, tissue engineering is greatly different from organ transplantation in terms of no use of immunosuppressant. The most important keywords featured in tissue engineering is 'living cells'.

Table 1 represents the tissues and organs being currently investigated in tissue engineering. Both tissue regeneration and organ substitution can be achieved both in vitro and in vivo (in situ), if appropriate techniques are employed. Clinically feasible in vitro tissue engineering is limited mostly to the skin regeneration and substitution of liver and pancreas. If tissues and organs can be regenerated in vitro on a large scale in response to the request from hospitals, it will be an ideal way. However, right now, this is practically impossible because of few knowledge available for in vitro tissue regeneration. Almost all attempts on tissue regeneration are being made in situ. Even in such a case, injection of mesenchymal blast cells and/or growth factors is mostly not enough to induce tissue regeneration even though the natural healing ability of the body backs it up. If the tissue defect is serious, it is at least essential for tissue regeneration and tissue substitution to construct an environment favourable for regeneration using devices. The materials and technologies required for tissue engineering are summarized in tables 2 and 3 . Among them are scaffolds (artificial extracellular matrix), carriers of growth factors, and barriers.

\section{Scaffold for cells and carrier for growth factors}

Generally, tissue regeneration needs artificial extracellular matrices (scaffolds) and blast cells, as shown in figures 2 and 3 , respectively. In addition, growth factors will be required in case tissue regeneration proceeds very slowly. Table 4 lists the growth factors involved in wound healing. The kind of cells and growth factors required for tissue engineering depends on the tissue to be regenerated and on the site where the tissue should be produced (in situ or in vitro). Both tissue allows us to explain figure 2 more clearly. When a defect is formed in the bone tissue, the defect will be occupied by fibrous tissues in case of no proper medical treatment. This is because the rate of fibrous tissue growth is generally much higher than that of the bone tissue. If this is the case, the formed fibrous tissue will not be substituted by the bone tissue, resulting in insignificant bone regeneration at the defect. One possible way to prevent the ingrowth of fibrous tissue into the site where the tissue is expected to regenerate, is to place a resorbable material into the defect. It may be ideal if this material functions as an artificial extracellular matrix, in other words, scaffold for ingrowth of bone-forming cells from the surrounding bone tissue and this exogenous extracellular matrix is resorbed harmonizing with the bone tissue regeneration. Such scaffolds can be prepared from 
naturally occurring biodegradable polymers (e.g. collagen, gelatin, and fibrin), synthetic biodegradable polymers (e.g. poly(lactic acid), poly(glycolic acid), and their copolymers), and inorganic substances (e.g. hydroxyapatite, calcium triphosphate, and calcium carbonate). They will all be used as formulations of porous type to facilitate ingrowth of a large number of cells.

If bone ingrowth does not occur as expected, a scaffold should be used in combination with cells and growth factors. Osteoblastic cells are isolated from the bone marrow, expanded in vitro, and incorporated into a porous scaffold. Since the half-life of growth factors in the body is very short, it will be extremely difficult to exert their inherent biological activity in vivo if they are simply injected. Thus, drug delivery systems (DDS) will become a very important technology, especially when a growth factor should be continuously released from a carrier for a certain period of time. Generally, the growth factortrapping carrier is incorporated into the scaffold and implanted into the defect. This technology will facilitate the sustained release of the growth factor at the site to be regenerated. Incorporation of a growth factor-trapping carrier and blast cells into an extracellular matrix together will also greatly promote tissue regeneration.

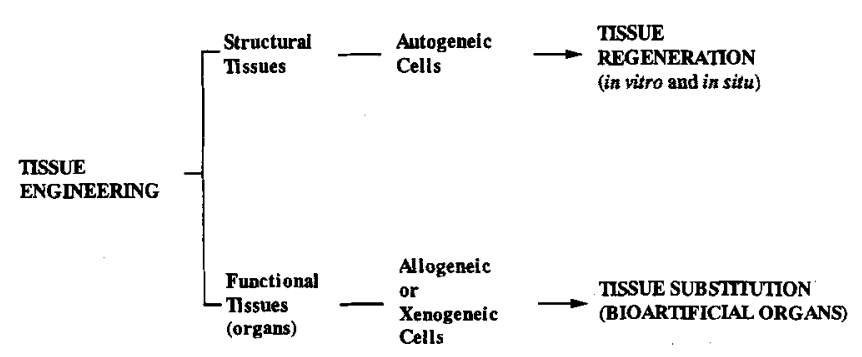

Figure 1. Two main purposes of tissue engineering.

\section{Barriers}

There are at least two types of barriers which are used for tissue regeneration and organ substitution. One is the barrier for making space to prevent the ingrowth of fibroblasts which produce collagenous fibrous tissues in the place where natural tissues should be regenerated. An example is the polymer membrane fixed around a periodontal defect for providing space to prevent gingiva infiltration so as to regenerate periodontium (guided tissue regeneration, (GTR)) and alveolar bone (guided bone regeneration, (GBR)). Some membranes have already been clinically used for these purposes. Resorbable polymer tubes are being studied as conduits for peripheral nerve reunion through regeneration.

The other is the immuno-isolative barrier. Currently, two kinds of organ substitution have been studied as demonstrated in table 5. One is for temporary use under extracorporeal blood circulation: the typical example is a device for liver assist, in other words, bioartificial liver. The other organ substitution is performed by a device that is permanently implanted to replace the lost biofunctions of organs. Microencapsulated islets of Langerhans have been most intensively studied for pancreas substitution, which is called bioartificial pancreas. Since allogeneic or xenogeneic cells are applied for these bioartificial organs, immuno-isolative membranes, as depicted in figure 4 , are needed as barriers to protect the transplanted foreign cells from the host's immune attack. The role of the membrane is illustrated in figure 5.

\section{Other factors influencing tissue engineering}

Tissue engineering is a practical science with the final goal of clinical application. Figure 6 shows the general steps required for a medical device development from

Table 1. Tissues currently under research.

\begin{tabular}{|c|c|c|c|c|c|}
\hline \multirow[b]{2}{*}{$\begin{array}{l}\text { Fabrication } \\
\text { site }\end{array}$} & \multirow[b]{2}{*}{$\begin{array}{l}\text { Cell } \\
\text { seeding }\end{array}$} & \multicolumn{3}{|c|}{ Tissue regeneration } & \multirow{2}{*}{$\begin{array}{l}\text { Organ substitution } \\
\text { Barrier } \\
\text { membrane }\end{array}$} \\
\hline & & Artificial ECM* & $\begin{array}{l}\text { Artificial } \mathrm{ECM}^{*}+ \\
\text { growth factors }\end{array}$ & $\begin{array}{l}\text { Barrier } \\
\text { membrane }\end{array}$ & \\
\hline in vitro & Necessary & Epidermis, dermis & & & $\begin{array}{l}\text { Liver, pancreas, } \\
\text { chromaffin cells }\end{array}$ \\
\hline \multirow[t]{2}{*}{ in situ } & Not necessary & $\begin{array}{l}\text { Dermis, ligament, } \\
\text { skull, spinal bone, } \\
\text { dura mater, esophagus }\end{array}$ & $\begin{array}{l}\text { Bone, peripheral } \\
\text { nerve, arteriole }\end{array}$ & $\begin{array}{l}\text { Periodontal tissue, } \\
\text { alveolar bone }\end{array}$ & \\
\hline & Necessary & $\begin{array}{l}\text { Skin (epidermis + dermis), } \\
\text { mandibula, small intestine, } \\
\text { myocardium, ureter, } \\
\text { bladder, artery }\end{array}$ & $\begin{array}{l}\text { Cartilage (fibrous and } \\
\text { hyaline), liver, meniscus, } \\
\text { breast, blood vessel }\end{array}$ & & \\
\hline
\end{tabular}

\footnotetext{
*Extracellular matrix.
} 
Table 2. Materials required for tissue engineering.

1. Scaffold (artificial extracellular matrix)

from porous, resorbable biomaterials for cell attachment, proliferation, and differentiation

2. Cells autologous, allogeneic, or xenogeneic; stem, progenitor, or differentiated

3. Cell growth factors for promotion of cell proliferation and differentiation

4. Carriers of growth factors for their sustained release

5. Barriers

for making space by preventing fibrous tissue ingrowth or for protecting heterogeneous cells from the host's immune attack

Table 3. Technologies required for tissue engineering.

1. Cell isolation in the intact and viable state

2. Cell culture on a large scale

3. Preservation of cells

4. Production of large amounts of growth factors

5. Sustained release of growth factors

6. Module design to allow high density cell seeding with sufficient nutrient supply

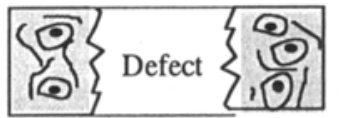

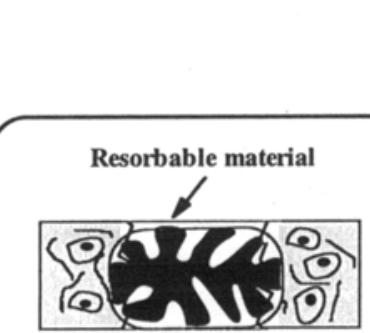

(a) without cultured cells and growth factor

O: Growth factor

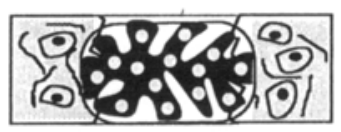

(c) with growth factor

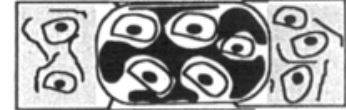

(b) with cultured cells

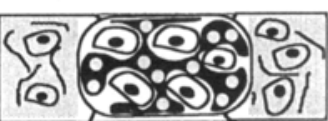

(d) with cultured cells and growth factor

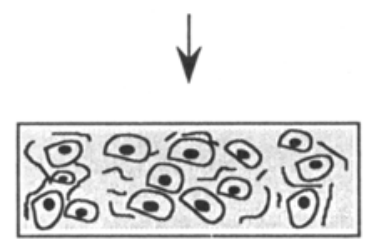

Figure 2. Principle of tissue regeneration using resorbable scaffolds.

Table 4. Growth factors for wound healing.

\begin{tabular}{|c|c|c|}
\hline Growth factor & Source & Primary target cells and effect \\
\hline EGF & Platelets & Keratinocyte motogen and mitogen \\
\hline TGF- $\alpha$ & Macrophages; keratinocytes & Keratinocyte motogen and mitogen \\
\hline HB-EGF & Macrophages & Keratinocyte and fibroblast mitogen \\
\hline FGFs 1,2 and 4 & $\begin{array}{l}\text { Macrophages and damaged } \\
\text { endothelial cells }\end{array}$ & Angiogenic and fibroblast mitogen \\
\hline FGF7 (KGF) & Dermal fibroblasts & Keratinocyte motogen and mitogen \\
\hline PDGF & $\begin{array}{l}\text { Platelets; macrophages; kera- } \\
\text { tinocytes }\end{array}$ & $\begin{array}{l}\text { Chemotactic for macrophages, fibroblasts; } \\
\text { macrophage activation, fibroblast mitogen, } \\
\text { and matrix production }\end{array}$ \\
\hline IGF-1 & Plasma; platelets & Endothelial cell and fibroblast mitogen \\
\hline VEGF & Keratinocytes; macrophages & Angiogenesis \\
\hline $\mathrm{TGF}_{-} \beta$ and $-\beta 2$ & Platelets; macrophages & $\begin{array}{l}\text { Keratinocyte migration; chemotactic for } \\
\text { macrophages and fibroblasts; fibroblast } \\
\text { matrix synthesis and remodeling }\end{array}$ \\
\hline TGF- $\beta 3$ & Macrophages & Antiscarring \\
\hline CTGF & Fibroblasts; endothelia & Fibroblasts; downstream of TGF- $\beta 1$ \\
\hline Activin & Fibroblasts; keratinocytes & Currently unknown \\
\hline IL- $1 \alpha$ and $-\beta$ & Neutrophils & $\begin{array}{l}\text { Early activators of growth factor } \\
\text { expression in macrophages, keratinocytes, } \\
\text { and fibroblasts }\end{array}$ \\
\hline TNF- $a$ & Neutrophils & Similar to the IL-Is \\
\hline
\end{tabular}

Reproduced from P Martin 1997 Science 276 75-81. 


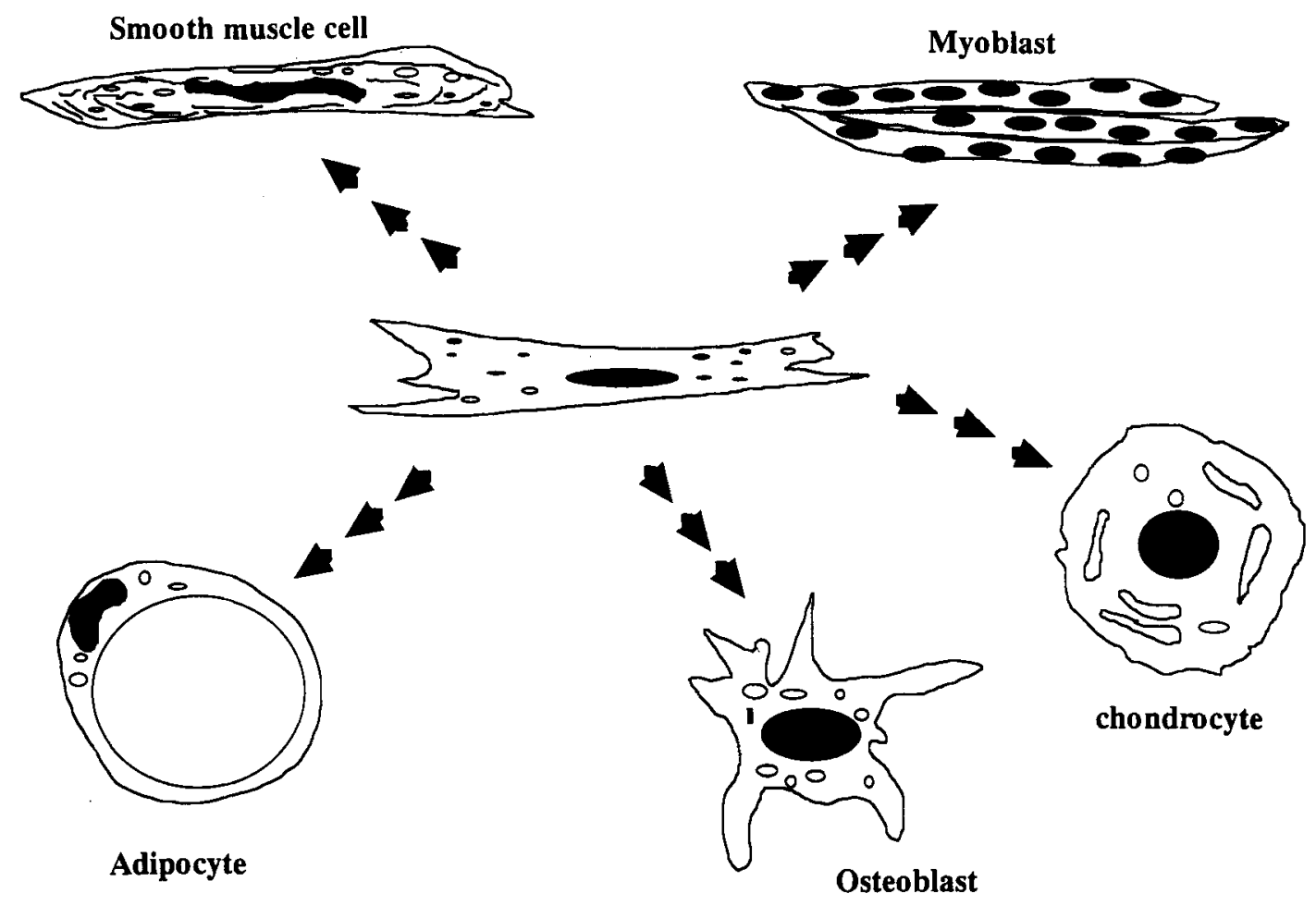

Figure 3. Mesenchymal blast cells used for tissue regeneration.

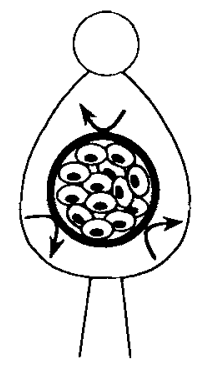

Tissue Substitution I (implantation)

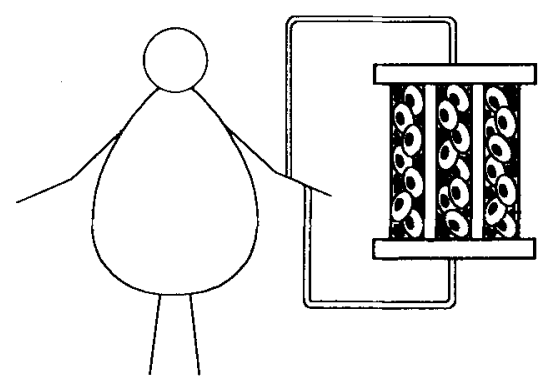

Tissue Substitution Il (extracorporeal circulation)

Figure 4. Organ substitution using cells and an immunoisolative membrane.

Table 5. Two types of organ substitutions using cells.

1. Temporary use

Extracorporeal blood circulation

(Liver assist device)

2. Permanent use

Cell transplantation

(Bioartificial pancreas)

its conception to its clinical application. Tissue engineered products also need many steps similar to those described in figure 6. If a problem appears in the course of these processes, it should be eliminated by all means. Otherwise,

it would become an obstacle that hinders progressing to the next further step. For the processes in tissue engineering, we need to consider factors of industrial and regulatory concerns other than those of materials and technologies described in tables 2 and 3. Any tissue engineering project will end up as a failure, if one of them is missing.

Other key factors are further required for promoting tissue engineering, as given in table 6 . The most crucial one is that governed by the environment surrounding the research project team. Raising funds is an important key factor for propulsion of tissue engineering project, but it should be kept in mind that sufficient research funding does not guarantee the achievement of the final goal of research project. To elucidate fundamental biological mechanisms involved in the tissue regeneration and organ formation is another key factor in tissue engineering. Interdisciplinary network beyond industrial and academic circles is critical for the research development and industrialization of tissue engineering. Probably, the last but not least important key factor is non-materialistic elements, which are given in table 7 .

\section{Conclusions}

Tissue engineering has been strongly driven forward in close cooperation between engineering and clinical medicine. The final objective of tissue engineering is to 


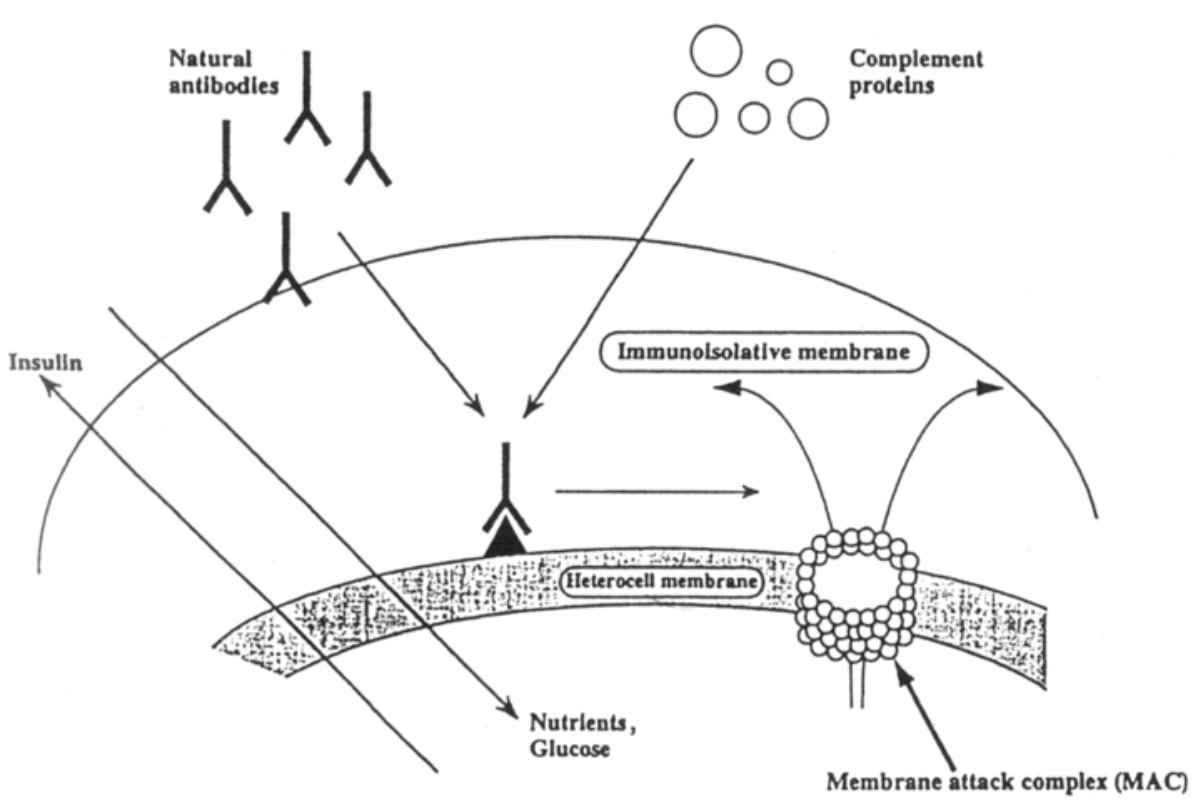

Figure 5. Functions of the immuno-isolative membrane.

Collect the needs of patients<smiles>[3H][AsH2]</smiles>

Synthesis, modification, processing, and characterization of Testing of biomaterials' non-toxicity with cells
and animals

Fabrication of the medical device

$\downarrow$

Evaluation of effectiveness using animals<smiles></smiles>

Clinical trials

1

Approval from regulatory organization

1

Manufacturing at plant

Figure 6. Processes from clinical needs to manufacturing of a medical device.

enhance the patient's quality of life using biological constructs of higher reliability, durability, and efficacy than the conventional artificial tissues and organs. However, long time periods will be needed to replace the conventional artificial tissues and organs with tissueengineered products, because the cooperation of engi-
Table 6. Other key factors in tissue engineering.

1. Funding, work force, space, time

2. Biomaterials, engineerings, biological resources (growth factors, cells, tissues), animal facilities

3. Fundamental mechanisms for tissue regeneration, organ formation, and immune defence

4. Interdisciplinary organization of network, industrial supports, regulations

Table 7. Non-materialistic key factors in tissue engineering.

Idea, philosophy, originality, passion, spirit, belief

neering and clinical medicine alone is not sufficient for successful achievement of tissue engineering. Tissue engineering research necessitates a variety of science and technology including not only clinical medicine and biomaterials, but also cell biology and biotechnology. In the initiation of tissue engineering research, the minimum knowledge concerning the biological mechanisms on tissue regeneration and organ formation is the lowest requirement. However, it is at present too unrealistic to expect a complete understanding of the regeneration mechanism. Nevertheless, we should struggle with tissue engineering research while repeating trials and errors without worrying about failure, as many patients have been waiting for the products. 